\section{The perception of information relevance ${ }^{1}$}

SIEGFRIED STREUFERT and SUSAN C. STREUFERT, Purdue University, Lafalette, Ind. 47907

The effect of experimentally induced information relevance on $S^{\prime}$ perception of information relevance and information importance in complex environments was investigated. Ss received 10 informative messages in each of four $1 / 2-h$ periods. Twenty per cent, $40 \%, 60 \%$, or $80 \%$ of that information was relevant (permitted meaningful responding). A constant $80 \%$ of all information was important. Ss' perceptions of information relevance and importance were obtained on rating scales. It was found that experimentally induced increasing relevance resulted in increasing perceptions of relevance and importance; however, perceptions of relevance and importance were higher than induced relevance at all but the $80 \%$ point.

Psychologists have for some time been concerned with the effect of information relevance on various measures of performance. Although the term, relevance, has been defined variously by researchers in signal detection, concept formation, perception, social psychology, and personality, some theoretical communalities and some similarities in research results have emerged (cf. Streufert \& Streufert, 1969). In some cases, however, comparisons among the various views are difficult to make since the relevance variable tends to have different meaning when information is presented to $\mathrm{Ss}$ in simple (unidimensional) forms and when information is presented in more complex (multidimensional) forms.

In simple tasks, relevant information is useful for obtaining or approaching the task solution. Irrelevant information cannot be used toward that end. For instance, in signal detection, a relevant stimulus should elicit a correct response; a response to the irrelevant stimulus (to noise) would be incorrect. In concept formation, information is viewed as relevant if it reduces uncertainty (in terms of information theory).

The meaning of relevance changes somewhat when stimulus configurations presented to the $\mathrm{S}$ become more complex (multidimensional). Here an item of relevant information would permit one of a number of meaningful responses or reduce uncertainty on one of a number of informational dimensions (cf. Archer, 1966). The greater the complexity of a stimulus array that is presented to a $S$ on the initial trial (that is, the more information on various dimensions is needed before a correct response can be made with certainty), the greater is the uncertainty of a $\mathbf{S}$ who is faced with the choice of a response, and the lower (on the average) is the quality of his task performance (Byers \& Davidson, 1968; Kepros \& Bourne, 1966). Increased uncertainty and decreased quality of task performance should be associated specifically with increases in relevant (rather than irrelevant) information or informational dimensions. Increases in irrelevant information should not affect uncertainty or task performance, as long as the $S$ is able to sort out relevant and irrelevant information.

Some researchers (e.g., Erlick, 1962; Hake, Rodwan, \& Weintraub, 1966; Haygood \& Stevenson, 1967; Howell, Johnston, \& Goldstein, 1966) have shown that increasing irrelevant information (or dimensions of irrelevant information) in complex settings also produces decrements in task performance. Adding irrelevant information in simpler environments (e.g., noise in some signal-detection studies) usually does not have this effect. Experimentally obtained decrements in task performance for $S$ s receiving additional irrelevant information in complex settings suggest that $S$ s either code irrelevant information as relevant or that information dimensions interact to produce relevance perceptions that are not in line with experimental relevance induction (e.g., information may reduce uncertainty on one dimension while adding uncertainty on another).

If difficulties arise in assuming equivalence of experimental relevance induction and subjective relevance perception for research in complex environments, then it may become necessary to measure subjective perceptions of information relevance in addition to establishing its objective (experimentally induced) counterpart. Does perceived information relevance in complex environments relate linearly to induced relevance? Higbee \& Streufert (1968) and Castore \& Streufert (1966) have shown that perceptions of success levels and failure levels in complex environments closely follow the curve for induced success and failure levels. Would the same relationships hold for perceived and induced relevance levels?

Relevant information has generally been conceived as information to which a $S$ can respond meaningfully within the context of his task. For research in complex tasks, another concept may have to be added; some information may inform the $S$ about his status but may not permit him to respond. This information would be important to the $\mathrm{S}$ but (if responses cannot be made) may not be relevant (in the psychological use of that term). All relevant information, by definition, would be important.

In this research, we are concerned with Ss' perceptions of both information relevance and information importance in a complex environment, when information relevance is experimentally varied and information importance is held constant.

\section{PROCEDURE}

Fifty-two paid undergraduate volunteers participated as pairs in the Tactical and Negotiations Game (TNG), a complex decision-making environment, developed by Streufert, Kliger, Castore, \& Driver (1967). The two-man teams were given responsibility for making military, economic, intelligence, and diplomatic decisions concerned with a small-scale internation conflict. Ss were told that they were playing the game against another team of Ss. In reality, the "strategy" of the enemy team was preprogrammed. All teams received the same informative messages in different random order. Validation for the procedures used in this experiment and data indicating face validity for the informative messages to which Ss were exposed are presented in Streufert, Castore, \& Kliger (1967) and Streufert \& Streufert (1969).

All teams received 10 informative messages equally spaced throughout four $1 / 2-h$ playing periods. Each message contained a single item of information. Eighty per cent of all messages were "important," that is, contained information about the status of Ss' performance. Messages were randomized independently for each team, except that $20 \%, 40 \%, 60 \%$, or $80 \%$ (randomized in order of periods and in message content) of the messages contained relevant information (messages permitting meaningful responding by the $\mathrm{Ss}$ ) ${ }^{2}$ All relevant messages were important messages. The four playing periods, although randomized in order of relevance levels, were played consecutively. They were interrupted only to let Ss fill out interim report forms, containing several scales. Among these were two 7-point scales on which Ss were asked to indicate the degree to which information they received during the last playing period was relevant and the degree to which it was important. ${ }^{3}$ Data analysis was based on scores obtained on these scales. 


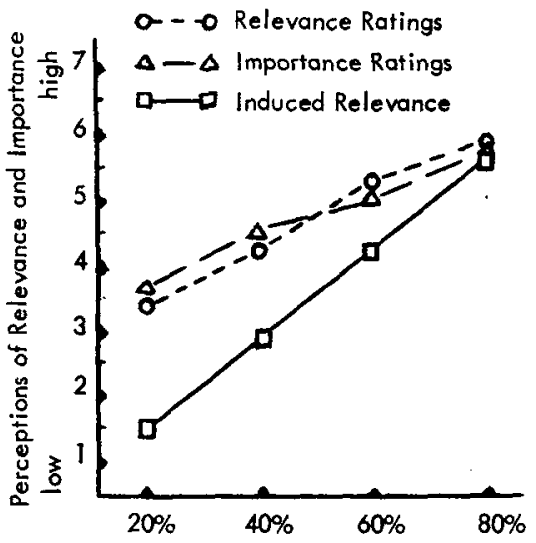

Proportion of Relevant Information

Fig. 1. The effect of experimentally induced information relevance on perceptions of relevance and importance.

\section{RESULTS AND DISCUSSION}

An entirely within two-way ANOVA for relevance vs importance ratings (Factor A) and four induced levels of information relevance (Factor $B$ ) resulted in significant $F$ ratios for the $B$ main effect $(F=76.12$, $\mathrm{df}=3 / 153, \mathrm{p}<.001)$ and for the $\mathrm{C}$ by $\mathrm{D}$ interaction $(\mathrm{F}=3.53 \mathrm{df}=3 / 153, \mathrm{p}<.05)$. Post hoc Newman-Keuls analysis for the B main effect indicated significant differences beyond $p<.05$ or .01 for differences between all induced relevance levels. Newman-Keuls tests for the A by B interaction did not substantiate differences between relevance ratings and importance ratings for induced relevance levels beyond those already described in the $B$ main effect. Consequently, we will not concern ourselves with the interaction effect. As shown in Fig. 1, perceived information relevance and importance increases as groups of Ss receive more information to which responding is possible. The increase in ratings of relevance and importance is near linear, particularly when the two curves are combined, obviating a potential need for trend analysis procedures.
Previous research of Higbee \& Streufert (1968) and of Castore \& Streufert (1966) has shown that experimentally induced success and experimentally induced failure result in primarily linear relationships between induced and perceived experimental conditions. However, in both cases, the perceived levels of success or failure closely follow location and slant of the curve for induced levels. In the present analysis (see Fig. 1), perceived relevance levels remain well above induced relevance, except at the point where induced relevance reaches $80 \%$ of all information presented to the Ss. We might conclude that Ss in complex environments can distinguish between differential induced relevance conditions but find it difficult to sort out all irrelevant information as actually irrelevant. ${ }^{4}$

Another interesting finding is the close correspondence between Ss' ratings of information relevance and information importance, even though relevance was experimentally varied and importance was held constant. It may well be that the action orientation required of $S s$ in the present task encouraged $S s$ to view information as unimportant, even though it gave them information about their current status, as long as the information did not lend itself to any respondent action on their part.

\section{REFERENCES}

ARCHER, E. J. The psychological nature of concepts. In $\mathrm{H}$. J. Klausmeier and C. W. Harris (Eds.), Analyses of concept learning. New York: Academic Press, 1966.

BYERS, J. L., \& DAVIDSON, R. E. Relevant and irrelevant information in concept attainment. Journal of Experimental Psychology, 1968, $76,283-287$.

CASTORE, C. H., \& STREUFERT, S. The perception of experimentally-induced failure. Psychonomic Science, 1966, 4, 137-138.

ERLICK, S. E. The ability to filter noise from a visual task when the noise and signal are presented sequentially. Journal of Experimental Psychology, 1962,63, 111-114.

HAKE, H. W., RODWAN, A., \& WEINTRAUB, D. J. Noise reduction in perception. In $K$. R. Hammond (Ed.), The psychology of Egon
Brunswick. New York: Holt, Rinehart \& Winston, 1966.

HAYGOOD, R. C., \& STEVENSON, M. Effects of number of irrelevant dimensions in nonconjunctive concept learning. Journal of Experimental Psychology, 1967, 74, 302-304.

HIGBEE, K. L., \& STREUFERT, S. The perception of experimentally-induced success. Psychonomic Science, 1968, 12, 361-362.

HOWELL, W. C, JOHNSTON, W. A., \& GOLDSTEIN, I. L. Complex monitoring and its relation to the classical problem of vigilance. Organizational Behavior \& Human Performance, 1966, 1, 129-150.

KEPROS, P. G., \& BOURNE, JR., L. E. Identification of biconditional concepts: Effects of number of relevant and irrelevant dimensions. Canadian Journal of Psychology, 1966, 20, 198-207.

STREUFERT, S., CASTORE, C. H., \& KLIGER, S. C. A tactical and negotiations game: Rationale, method, and analysis. Rutgers University: ONR Technical Report No. 1, 1967.

STREUFERT, S., KLIGER, S. C., CASTORE, C. H., \& DRIVER, M. J. A tactical and negotiations game for the analysis of decision integration across decision areas. Psychological Reports, 1967, 20, 155-157.

STREUFERT, S., \& STREUFERT, S. C. The effect of conceptual structure, failure, and success on attribution of causality and interpersonal attitudes. Journal of Personality \& Social Psychology, 1969, 11, 138-147.

\section{NOTES}

1. This work was sumnorted by a contract between the Office of Naval Research and Purdue University.

2. Data analysis indicated that $S s$ made more responses to relevant informative messages than they made to irrelevant informative messages $(p<.001)$.

3. Before beginning participation in the TNG, Ss were given an example of the meaning of "relevance" and "importance." They were told that information that his plane was about to crash would be relevant to the pilot of the plane (he might act to avert the situation) but not to the passengers (they cannot respond meaningfully to the situation). The information would be important to both pilot and passengers since all their lives were at stake.

4. We are assuming that constancy of the environment and of the seven-point rating scales for the three experiments is sufficient justification for our conclusion that Ss would have used lower scale values had they perceived relevance levels in that fashion. 